7. Reprod. Fert. (1970) 22, 193-198

\title{
OBSERVATIONS ON SOME PROPERTIES OF A POTENT SPERM-HEAD AGGLUTININ IN THE SEMEN OF A FERTILE RABBIT
}

\author{
J. M. BEDFORD* \\ Worcester Foundation for Experimental Biology, \\ Shrewsbury, Mass. 01545 \\ (Received 5th May 1969)
}

\begin{abstract}
Summary. A potent agglutinin in the semen of a fertile male rabbit caused massive head-to-head agglutination of its own ejaculated spermatozoa and those of other rabbits, without reducing their motility, or destroying their fertility. By contrast, rabbit spermatozoa collected from the uterus $12 \mathrm{hr}$ after insemination, and bull, rat, hamster, guineapig and human spermatozoa, were immobilized immediately when exposed to the active seminal plasma, the agglutinating and spermicidal properties of which were destroyed by heating to $55^{\circ} \mathrm{G}$ for $20 \mathrm{~min}$. This indicates a specific change in the susceptibilities as well as in the functional competence of rabbit spermatozoa during the period of capacitation in the uterus. The agglutinin-active plasma also brought about marked clumping of leucocytes, but not of erythrocytes or granulosa cells. Brief comment is made on the nature of the sperm surface and on the significance of seminal antagglutins.
\end{abstract}

\section{INTRODUCTION}

The innate tendency of most mammalian spermatozoa for head auto-agglutination is prevented in the normal ejaculate by antagglutins (Kato, 1936; Lindahl \& Kihlström, 1954) which apparently act to mask the 'sticky' surface of the sperm head. From time to time, marked agglutination of ejaculated spermatozoa has been reported, particularly in man where this has sometimes been associated with male sterility (Wilson, 1954, 1956; Rumke \& Hellinga, 1959; Fjallbrant, 1965, 1968). In occasional samples of rabbit semen, a proportion of actively moving spermatozoa agglutinates by the head surface (personal observation), but this is not common and is not an intense reaction. For this reason, it seemed of interest to comment on spermicidal and other properties of a spontaneously occurring, potent, sperm-head agglutinin, which was observed by chance to be present in the semen of a fertile New Zealand White rabbit.

\section{OBSERVATIONS}

\section{Agglutination}

After collection of an ejaculate from the affected male with an artificial

* Present address: Department of Anatomy, and International Institute of Human Reproduction, Columbia College of Physicians and Surgeons, New York. 
vagina, agglutination of the actively moving spermatozoa began to occur immediately; this reaction progressed rapidly at room temperature and after several minutes, the great majority $(>80 \%)$ of moving spermatozoa were associated by their heads in groups of from three to four to as many as forty to fifty spermatozoa (Pl. 1, Figs. 1 and 2). The spermatozoa in the larger aggregates sometimes tended to become aligned in parallel and together moved rapidly across the field. The fact that a similar agglutination reaction was observed immediately when spermatozoa from the cauda epididymidis were mixed with seminal plasma from the affected male, indicates that the agglutination reaction involved elements on the sperm surface itself and not elements which had been secondarily adsorbed from the accessory glands. The aggregates of spermatozoa were partly dissociated by shaking, but re-formed subsequently. The motility of the agglutinated spermatozoa in slide preparations, at room temperature (about $23^{\circ} \mathrm{C}$ ), or in Carrel flasks at $37^{\circ} \mathrm{C}$, did not diminish more quickly than that of spermatozoa in normal semen subjected to the same conditions. Eventually, as their motility declined in slide preparations (after 1 to $2 \mathrm{hr}$ ), the sperm masses formed flocculent rings with other particulate matter in the semen (Pl. 1, Fig. 3).

The intense agglutination did not merely reflect the congenital absence of seminal antagglutins, and seemed to be brought about by a specific agent, for ejaculated spermatozoa from other rabbits remained motile but became agglutinated in the same way when mixed with the active seminal plasma. With the most potent samples of the agglutinin-active plasma, agglutination was still induced to some degree when one volume of active plasma was added to six volumes of normal semen.

The active seminal plasma induced rapid clumping when added to suspensions of rabbit leucocytes obtained as the 'buffy coat' from venous blood (Pl. 1, Figs. 4 and 5), but no such agglutination effect was observed with suspensions of rabbit erythrocytes or granulosa cells from fresh rabbit ova. Normal rabbit seminal plasma had no agglutinating effect on suspensions of white blood cells (Pl. 1, Fig. 6). The most potent agglutinating activity was associated with a faint golden tinge in the ejaculate, which remained in the clear plasma after centrifugation. This slight tinge was also sometimes present throughout the seminal jelly; when this jelly was washed in Ringer solution and dissolved with gelatinase, the resulting solution displayed strong agglutinating activity against spermatozoa and white blood cells. Since this jelly is formed in the seminal vesicles, the active agglutinin was probably formed, at least in part, at this site.

\section{EXPLANATION OF PLATE 1}

Figs. 1 and 2. Ejaculated spermatozoa of agglutinin-active male. Note the widespread head-to-head agglutination. Fig. $1 \times 140$. Fig. $2 \times 300$.

FIG. 3. Formation in semen of flocculent rings of spermatozoa and débris as sperm motility deteriorates after 1 to $2 \mathrm{hr}$ on slide. $\times 400$.

Figs. 4 and 5. Agglutinated clumps of leucocytes suspended in the agglutinin-active seminal plasma. Fig. $4 \times 75$. Fig. $5 \times 120$.

Fic. 6. Absence of agglutination among leucocytes suspended in normal rabbit seminal plasma. $\times 100$. 
PIAIF,
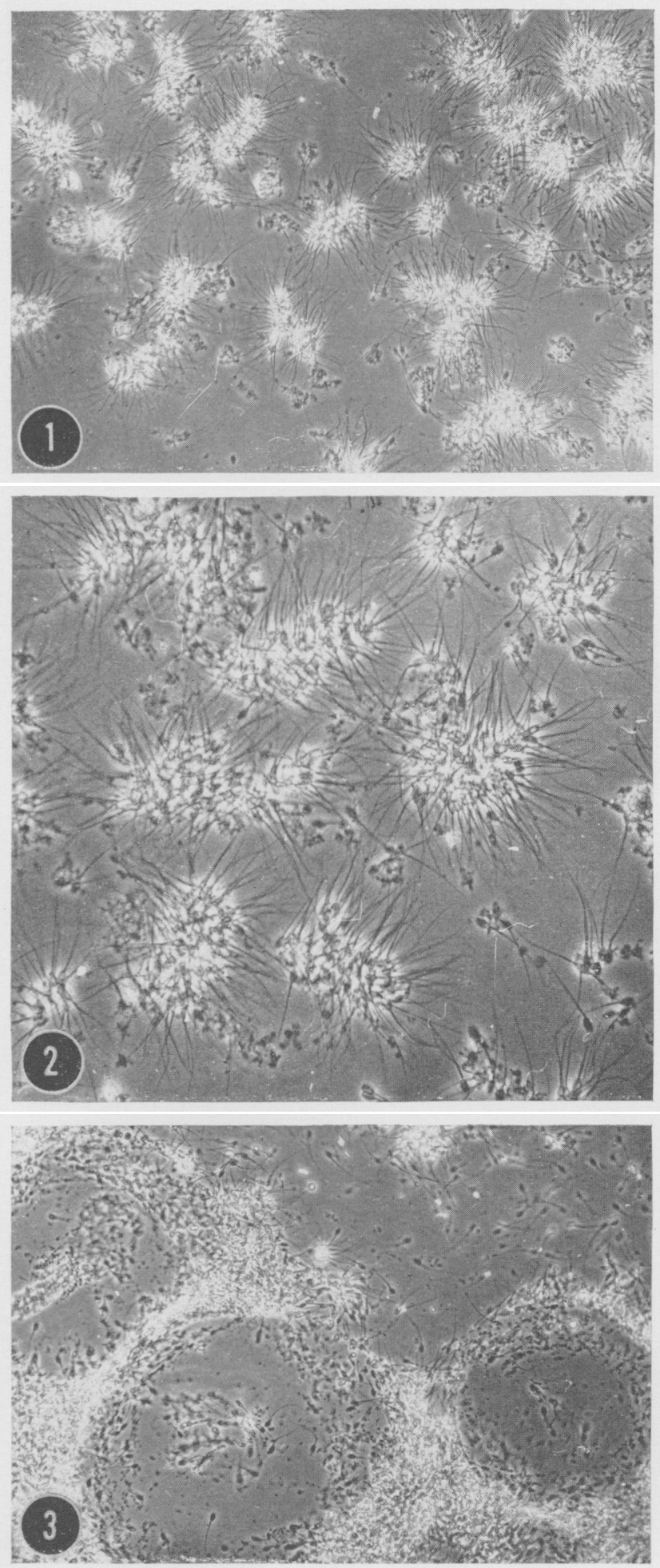

Fining t. 194
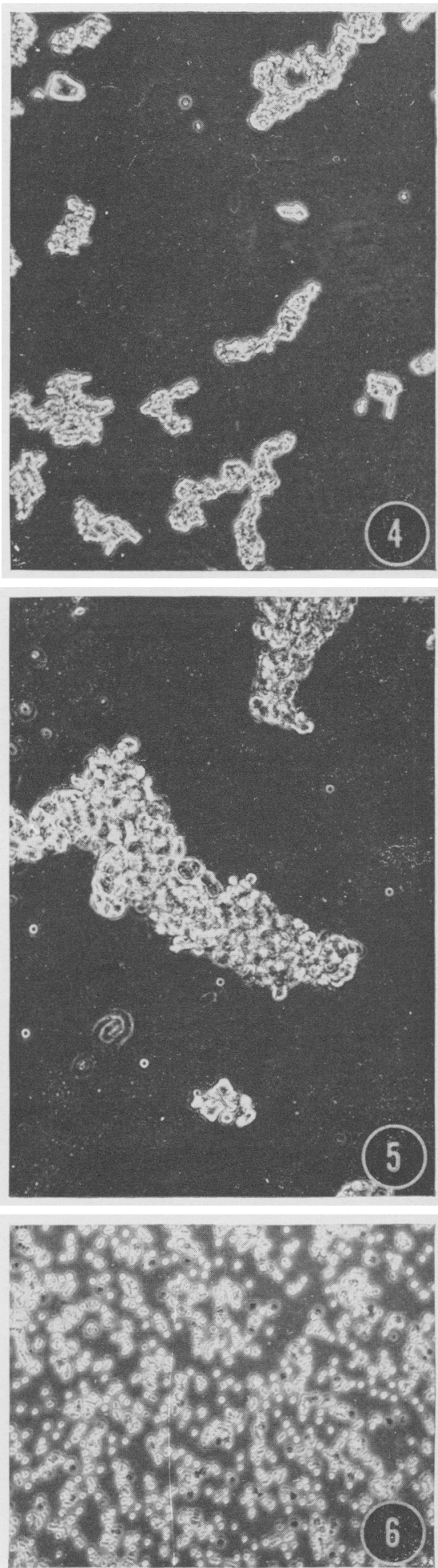
Several observations point to the likelihood that the active agglutinin was bound by the agglutination reaction, perhaps as a result of adsorption to the cell surface. Serial passage of concentrated cauda epididymal spermatozoa through the active plasma served to remove its agglutinating (and spermicidal - see below) activity. Likewise, a more potent agglutinating plasma was obtained by centrifugation of the ejaculate immediately after collection, compared with aliquots allowed to react for $1 \mathrm{hr}$ before centrifugation of spermatozoa from the plasma.

In six samples of active plasma tested, the ability to agglutinate spermatozoa or leucocytes was abolished by heating to $55^{\circ} \mathrm{C}$ for $20 \mathrm{~min}$.

\section{Fertility}

The fertility of the affected male did not seem to be noticeably influenced by the condition described above. Two females were each inseminated, respectively, with 3.5 and $5.0 \times 10^{6}$ spermatozoa into the vagina, and were injected with $100 \mathrm{i}$.u. of human chorionic gonadotrophin. The ova from these females were fertilized normally (seven/seven and eight/eight), when examined 20 to $22 \mathrm{hr}$ later. Two other females mated by the affected male produced litters of six and seven young, respectively. Five male offspring in one litter subsequently showed no evidence of agglutinating activity in their semen.

These observations were terminated by the death of the affected male almost 5 months after discovery of the condition. There was no evidence at autopsy of any abnormality of the accessory glands or the reproductive tract.

\section{Spermicidal activity}

As a first step to determine whether the agglutinin-active plasma also possessed decapacitation activity (Ghang, 1957), sperm suspensions flushed with Ringer solution from the uterus, $12 \mathrm{hr}$ after mating, were mixed $4: 1$ by volume with the active seminal plasma. Unexpectedly, all the spermatozoa in the uterine flush immediately became irreversibly immotile after this treatment, whereas spermatozoa from the same sample remained motile when tested against normal seminal plasma. In the phase microscope, no consistent change was observed in the morphology of the immobilized uterine spermatozoa (or in foreign spermatozoa-see below) after their exposure to the active seminal plasma. This demonstration of seminal plasma spermicidal activity specific to uterine, but not to ejaculated or to epididymal spermatozoa, was repeated in six further experiments, including two experiments with uterine spermatozoa originally ejaculated by the male in question.

These observations suggested the development of a susceptibility of rabbit spermatozoa to the active seminal plasma, during their residence in the uterus, but this could have been due to factors associated with ageing of the spermatozoa during their $12 \mathrm{hr}$ in the uterus. The agglutinin-active plasma was tested in two experiments, therefore, in a ratio of $1: 1$ against ejaculate and epididymal spermatozoa (approximately 2 to $3 \times 10^{6}$ spermatozoa/ml), cultured in Tyrode $+10 \%$ heated serum at $37^{\circ} \mathrm{C}$ for $12 \mathrm{hr}$, and also against spermatozoa from the same samples recovered from the uterus about $12 \mathrm{hr}$ after artificial insemination per vaginam. As before, the spermatozoa recovered after $12 \mathrm{hr}$ in 
vivo were killed by exposure to the active plasma, whereas the spermatozoa from the same samples cultured in vitro showed no depression of motility, when mixed with the agglutinin-active plasma.

The agglutinin-active plasma was tested also against ejaculated or mature epididymal spermatozoa from the bull, rat, guinea-pig, cat, hamster, man and mouse. Though spermatozoa from all these species survived for varying periods in seminal plasma from normal male rabbits, all but mouse spermatozoa were immobilized in less than $30 \mathrm{sec}$ when one or two drops containing 5 to 25 $\times 10^{6}$ spermatozoa were mixed with $1 \mathrm{ml}$ of the agglutinin-active plasma. Mouse spermatozoa were somewhat depressed by this treatment, but some remained motile after 10 to $15 \mathrm{~min}$ in the active plasma.

The spermicidal potential of the active plasma against both rabbit uterine spermatozoa, and also against heterologous spermatozoa, was always destroyed by heating to $55^{\circ} \mathrm{C}$ for $20 \mathrm{~min}$.

\section{DISCUSSION}

Several agents will promote head agglutination of rabbit spermatozoa, including di- and tri-valent cations (Yamane, 1921), anti-histamines such as mepyramine maleate and diphenhydramine $\mathrm{HCl}$ (unpublished), certain myxo-viruses, normal heated homologous serum, and agglutinating antibody induced against head-specific antigens (Henle, Henle \& Chambers, 1938; Smith, 1949). In the present case, the aetiology of the condition and nature of the active principle in the seminal plasma are not clear. An attempt was made to detect abnormal components in the active seminal plasma using acrylamidegel electrophoresis. The active plasma showed no consistent difference in its electrophoretic components, with the notable exception of a heavy pre-albumin band which was sometimes absent and never equalled in intensity in any control samples of seminal plasma. It is not certain whether the agglutinating and spermicidal properties of the active semen involved one or more elements, for, although both spermicidal and agglutinating effects were removed by the same treatments, cytotoxic antibodies against spermatozoa apparently can occur independently of sperm agglutinins in serum (Hamerlynck \& Rumke, 1968). Cytotoxic antibodies are frequently complement-dependent, as has been shown to be the case for the spermatotoxic auto-antibody in guinea-pig serum (Johnson, 1968), and the possibility arises that complement might have been involved in the spermatotoxic action of the agglutinin-active plasma. For this reason, fresh rabbit and bull seminal plasma, and undiluted fresh rabbit uterine fluid collected $12 \mathrm{hr}$ after natural mating, were tested for the presence of complement. There appears to be no trace of complement in these secretions, as judged by the consistent absence of any haemolysis in the standard sheep red cell test for complement fixation. It is unlikely, therefore, that the spermicidal reactions described in this report could have been complement-dependent. Present observations also suggest a difference between the agglutinin-active spermicidal system in the rabbit seminal plasma, and the spermicidal and sperm head agglutinating factors present in normal rabbit spermatozoa. The spermatotoxic activity of fresh normal serum kills ejaculated rabbit spermatozoa 
(Chang, 1947), whereas the agglutinin-active seminal plasma does not do so; furthermore, heating to $55^{\circ} \mathrm{C}$ in no way alters the ability of normal serum to bring about avid head-to-head agglutination of ejaculated or epididymal spermatozoa, yet this property of the agglutinin-active seminal plasma was totally removed by such heat treatment.

These observations raise three points worthy of comment. First, the normal fertilizing ability of the agglutinated rabbit semen was perhaps surprising in view of the conclusion that antagglutins are of importance for fertility (Lindahl \& Kihlström, 1954), though Fjallbrant (1968) has drawn attention to the fact that seminal sperm agglutinins do not necessarily result in impaired fertility in men. Epididymal rabbit spermatozoa in heated serum also show marked head agglutination and yet consistently achieve a high fertilization rate when inseminated in relatively small numbers (personal observation). In both these cases in the rabbit, the numbers of spermatozoa recovered in the uterine flush $12 \mathrm{hr}$ after insemination of the agglutinated samples were not significantly different from normal, and these for the most part were swimming as individuals, or were adherent to leucocytes. This indicates that both types of agglutination may have been reversed to some degree in the female tract; nevertheless, the functional importance of antagglutins in rabbit seminal plasma may have been somewhat over-emphasized in the past.

The second point concerns the nature of the cell surface. Erythrocytes and myeloid leucocytes differ in their surface properties (Mudd \& Mudd, 1931; Bangham, Pethica \& Seaman, 1958) and, in the present study, the lack of response of erythrocytes and granulosa cells to the seminal agglutinin stands in contrast to the avid agglutination manifested by the leucocytes and sperm heads. The classic studies of Wilson (1907), using sponge cells, and subsequent investigations by others using embryonic tissues for the most part (see Steinberg, 1962), have demonstrated clearly the tendency of many cell types to adhere preferentially to like cells. Since polymorphonuclear leucocytes and sperm heads show a marked tendency for auto-agglutination, for adhesion to glass, and for adhesion to each other, it is possible that the architecture and nature of the charged groups at the surface of the leucocyte and the sperm head may prove to be very similar.

The inadvertent finding that rabbit spermatozoa recovered from the uterus had apparently developed a lethal sensitivity to the agglutinin-active seminal plasma during the period in which capacitation is accomplished was of particular interest. In view of the fact that current evidence begins to point to the involvement of changes in the sperm plasma membrane as a facet of capacitation, (Bedford, 1968), it is noteworthy that the active toxic principle was associated with strong surface-agglutinating activity in the seminal plasma. These observations introduce the notion that spermatozoa, which have been resident in the female for some hours, undergo specific change in their susceptibilities as well as in their functional capacity. This idea may well have relevance in some instances of unexplained female infertility and in the current search for new methods of approach to the question of contraception. 


\section{ACKNOWLEDGMENTS}

This study was supported by NIH grant HD-03472 awarded to Dr M. G. Chang.

The author wishes to thank Dr S. M. Beiser, Department of Microbiology, Columbia University College of Physicians and Surgeons, for testing the samples of rabbit and bull seminal plasma and rabbit uterine fluid for the presence of complement.

\section{REFERENCES}

Bangham, A. D., Pethica, B. A. \& Seaman, G. V. F. (1958) The charged groups at the interface of some blood cells. Biochem. 7. 69, 12.

BEDFORD, J. M. (1968) Ultrastructural changes in the sperm-head during fertilization in the rabbit. Am. 7. Anat. 123, 329.

Chang, M. C. (1947) The effects of serum on spermatozoa. 7. gen. Physiol. 30, 321.

Chang, M. C. (1957) A detrimental effect of seminal plasma on the fertilizing capacity of sperm. Nature, Lond. 179, 238.

Fjallbrant, B. (1965) Immunoagglutination of sperm in cases of sterility. Acta obstet. gynec. scand. 49, 474.

Fjallbrant, B. (1968) Sperm agglutinins in sterile and fertile men. Acta obstet. gynec. scand. 47, 89.

HAMERLYNCK, J. \& RuMke, P. (1968) A test for the detection of cytotoxic antibodies to spermatozoa in man. F. Reprod. Fert. 17, 191.

Henle, W., Henle, G. \& Chambers, L. A. (1938) Studies on the antigenic structure of some mammalian spermatozoa. F. $\exp$. Med. 68, 335.

Johnson, M. H. (1968) Characterization of a natural antibody in normal guinea-pig serum reacting with homologous spermatozoa. F. Reprod. Fert. 16, 503.

KATo, K. (1936) Experimental studies on the agglutination of mammalian spermatozoa with special reference to its bearing upon fertilization. Mem. Fac. Sci. Agric. Taihoku imp. Univ. 19, 1.

LINDAHL, P. E. \& KinLSTRÖM, J. E. (1954) An antiagglutinic factor in mammalian sperm plasma. Fert. Steril. 5, 241.

Mudd, S. \& Mudd, E. B. H. (1931) The deformability and the wetting properties of leucocytes and erythrocytes. F. gen. Physiol. 14, 733.

Rumke, P. \& Helinga, G. (1959) Autoantibodies against spermatozoa in sterile men. Am. J. clin. Path. 37, 357.

SMITH, A. U. (1949) Some antigenic properties of mammalian spermatozoa. Proc. R. Soc. B, 136, 46.

Steinberg, M. S. (1962) On the mechanism of tissue reconstruction by dissociated cells. 1. Population kinetics, differential adhesiveness, and the absence of directed migration. Proc. natn. Acad. Sci. U.S.A. 48, 1577.

Wilson, H. V. (1907) On some phenomena of coalescence and regeneration in sponges. F. exp. Zool. $5,245$.

WiLson, L. (1954) Sperm agglutins in human semen and blood. Proc. Soc. exp. Biol. Med. 85, 652.

WiLson, L. (1956) Sperm agglutination due to autoantibodies. Fert. Steril. 7, 262.

Yamane, J. (1921) Physical and chemical properties of horse semen with special reference to the physiology of the spermatozoa. F. Coll. Agric. Hokkaido imp. Univ. 8, 161. 